\title{
Evaluation of hydration indexes in kale leaves
}

\author{
Adonai G. Calbo and Marcos D. Ferreira
}

*Corresponding author: Tel: +55-16-2107-2801; Fax.: 55-16-2107-2902; e-mail: adonai@cnpdia.embrapa.br

Received: 02 May 2011; Accepted: 23 July 2011

\begin{abstract}
Hydration indexes are practical variables for quantifying plant water stress and can be useful for agronomic purposes. Three adapted hydration indexes based on relative water content, volumetric hydration, and leaf turgor pressure were evaluated in kale (Brassica oleracea var. acephala) leaf segments. Relative water content and volumetric hydration were measured in leaf segments after a water infiltration procedure with the aim of filling its large intercellular volumes $(\cong 18 \% \mathrm{v} / \mathrm{v})$. The infiltration was done using a hydrostatic weighing procedure and with the aid of vacuum to fully hydrate the leaf segments. These two relative indexes were proportional to the transpiration-induced leaf water loss. The third index, turgor pressure, was measured with a Wiltmeter ${ }^{\circledR}$ instrument. Similarly, the turgor pressure was proportional to the leaf water loss, and it decreased from $\cong 310 \mathrm{kPa}$ in recently harvested leaves to zero in dehydrated leaves, after a total water loss of $\cong 23 \%$. Turgor pressure was correlated with the other two hydration indexes using approximations of leaf volumetric elastic modules. Similar estimates were obtained because the decline between turgor pressure and the natural logarithm of these relative leaf hydration indexes was numerically similar ( $\cong 900 \mathrm{kPa})$. However, the volumetric hydration index seemed to be more suitable as a model, not only for being more concise but also because it showed a clearer biomechanical representation of the leaf water deficit effects.
\end{abstract}

Key words: Brassica oleracea, intercellular air volume, volumetric hydration, relative water content, turgor pressure, leaf volumetric elastic modules, Wiltmeter.

\section{INTRODUCTION}

Dehydration indexes have high practical agronomic and postharvest importance, and therefore, the development of new measurement methods is crucial for their application. Here, we examined a water infiltration method developed by Czersky (1964 and 1968) to expedite the measurement of relative water content, and we assessed the performance of a new portable Wiltmeter ${ }^{\circledR}$ instrument, which is suitable for rapid field measurement of leaf turgor pressure (Calbo, 2009; Calbo et al., 2010).

Czersky (1964 and 1968) observed that water infiltration after a vacuum treatment was an interesting method to rapidly alleviate plant water tension by directly exposing cells to free water introduced into intercellular volumes. Using this effect, Czersky was able to rapidly obtain full reference tissue hydration, which was a considerable advance in comparison with traditional procedures in which hydration occurs on a time scale of hours or days (Slavíck, 1974).

By definition, tissue relative water content is calculated with the expression:

$$
{ }^{\star} R=\left(m-m_{S}\right) /\left(m_{H}-m_{S}\right) \quad \text { eq. } 1
$$

where $m_{H}$ is the fully hydrated leaf weight, $m$ is the natural leaf weight, and $m_{S}$ is the leaf dry weight.

With water introduced directly into the intercellular volumes by a vacuum treatment, however, equation 1 needs to be modified to include this additional water weight $\left(m_{w}\right)$. Czersky (1964 and 1968) included that modification by 
estimating $m_{W}$ according to the air volume removed from leaf segments by a vacuum treatment. This measurement was made using a funnel graduated at the top to allow the measurement of the leaf vacuum-expelled air volume soon after the return to the local barometric pressure. With this procedure Czersky estimated the leaf hydrated weight $\left(m_{H}\right)$ with the expression:

$$
m_{H}=m_{l}-m_{W} \quad \text { eq. } 2
$$

where $m_{l}$ is the water infiltrated tissue weight and $m_{W}$ is the water weight estimated as the product of the collected air volume by the water density, assuming that all intercellular air volumes were filled with water. Consequently, according to this procedure developed by Czersky, the relative water content could be written as:

$$
{ }^{\star} R=\left(m-m_{s}\right) /\left(m_{l}-m_{W}-m_{s}\right) \quad \text { eq. } 3
$$

However, one problem of the Czersky procedure is that most of the gases dissolved inside cells are extracted along with the air present in intercellular air volumes (Calbo \& Sommer, 1987; Calbo \& Nery, 1994); hence, the estimate of $m_{w}$ in equation 2 is overestimated. A second limitation of the original Czersky procedure is the possibility that only a part of the leaf intercellular volumes is filled up with water, a factor that would cause an underestimation of $m_{w}$. Therefore, a better estimate of $m_{W}$ can be obtained if the intercellular air volume of the tissue is measured by a differential mass and volume method (Calbo \& Nery, 1995), which also enables the estimation of $m_{H}$ (equation 2 ), even in cases where the intercellular water infiltration is incomplete.

The relative water content is a traditional plant physiology variable because it depends only on weighing measurements and, therefore, can be obtained in any laboratory with a scale and an oven. Despite its simplicity, Slavík (1974) points out that measuring the relative water content is a slow and toilsome procedure plagued with errors, such as insufficient hydration and the occurrence of significant tissue growth. Both errors are related to the seemingly simple method used to hydrate sample tissue segments to estimate of $m_{H}$, that is, by allowing the tissue to absorb water from a moist substrate.

Therefore, new hydration indexes with better performance will be welcomed by agronomists and horticulturists. Conceptually, different biometrical variables, such as volume, density, turgor pressure, and apoplastic water tension, or aggregated variables, such as the resulting cell wall tension (Lockhart, 1965; Calbo \& Pessoa, 1994; Pessoa \& Calbo, 2004), could be used to create new hydration indexes. Although the measurement of such variables is not simple, difficulties related to the measurement of volumes in particular are, however, being overcome with the evolution of three-dimensional image analyses (Sun, 2008). Therefore, simple hydration indexes, such as the volumetric hydration index (equation 4), may became more practical in the near future. For instance,

$$
* V=v / v_{H} \quad \text { eq. } 4
$$

where $* V$ is the volumetric hydration, $v$ is the current organ volume, and $v_{H}$ is the fully hydrated organ volume. The appealing force of equation 4 resides in its simple dependence on the organ volume $(v)$, which is the variable that governs the intracellular pressure (equation 5) (Husken et al., 1978, Murphy \& Ortega, 1995 e 1996).

$$
E=d P_{S} / d \operatorname{Ln}(v) \cong \Delta P_{S} /(\Delta v / v) \quad \text { eq. } 5
$$

where $E$ represents volumetric elastic modules, $P_{S}$ is the intracellular turgor pressure, and $v$ is the intracellular cell volume or the symplastic organ volume, when the concept is applied to a leaf, for example. For practical applications, however, it is easier to measure the total organ volume than its symplasmic volume, which would be a conceptually more suitable way to apply equation 5 . For organs with thin walled cells and with small intercellular air volumes, that fine conceptual difference could be disregarded while obtaining meaningful information about the plant water deficit with aid of equations 4 and 5 . There are also other approximated assumptions that have been used to apply equation 5 ; for instance, the assumption that the organ volume changes in proportion to its water content (Murphy \& Ortega, 1995). As with any approximation, it involves errors, and an important one comes from implicitly assuming that the density of an organ does not change as it loses water; however, water density is different from the density of cell components, such as the cell wall, or the intercellular air volumes. Such density error may not be too high if water loss is below $25 \%$ and if the intercellular air volume fraction can be considered stable. According to Calbo and Nery (2001), intercellular volume can be considered stable in a process 
such as dehydration whenever changes in organ volume occur proportionally to the intercellular volume changes. In other words, the parameters that link plant stress and intercellular volume stability are of geometric nature and are still unknown for most plant organs.

A portable instrument for evaluating leaf turgor pressure was recently developed, and it is called the Wiltmeter $^{\circledR}$; this device can be a valuable tool in plant hydration studies. With this instrument, the smallest leaf compression $\left(p_{0}\right)$ that blocks the air passage is an estimate of leaf turgor. When comparing Wiltmeter ${ }^{\circledR}$ measurements with pressure probe measurements, Calbo et al. (2010) observed linear relationships, with a decline close to one, when these methods were applied to detached leaves of lettuce (Lactuca sativa L.), kale (Brassica oleracea L. var. acephala), and chicory (Chichorium endivia L.) subjected to air dehydration. This field succedaneum of the pressure probe might be a valuable instrument considering that cell turgor pressure and cell volume are functionally related by elastic volumetric modules (Murphy \& Ortega, 1995). Here, adaptations for rapid evaluation of relative water content, volumetric hydration and turgor pressure with a Wiltmeter ${ }^{\circledR}$ instrument were studied using kale (Brassica oleracea var. acephala) leaf segments as a model. The aim of this study was to evaluate the errors and approximations involved in these rapid methods, which are potentially valuable for studies of plant ecophysiology and postharvest physiology.

\section{MATERIAL AND METHODS}

Plant Material: Kale leaves (Brassica oleracea var. acephala cv. Manteiga) were harvested in the morning, organized in bunches of about 15 leaves, placed in a thermal box and brought to the postharvest laboratory at Embrapa Instrumentation. The leaves were maintained at $25 \pm 2^{\circ} \mathrm{C}$ with a relative humidity above $90 \%$ before use.

The leaf segments were obtained by cutting out the main vein and were placed over a bench under natural conditions $\left(25 \pm 2^{\circ} \mathrm{C}\right.$ and relative humidity of $\left.65 \pm 10 \%\right)$ to allow rapid water loss. As the segments lost weight, the turgor pressure was evaluated with a Wiltmeter ${ }^{\circledR}$ (Calbo et al., 2010) in a completely randomized assay with five replications. Similarly, leaf weight and leaf segment volume were measured by hydrostatic weighing while the leaves lose water. As is described below, those evaluations were used to estimate the volumetric hydration and relative water content. A regression analysis was used to examine the observed relationship among the studied variables.

Apparent weight and volume: Hydrostatic leaf weight (Figure 1) was measured with an implement containing the following parts: a small hook-ended screw fixed underneath the balance load cell that enables hydrostatic weighing by hanging a sample holder made with a round net fixed to a metallic base from a $0.1 \mathrm{~mm}$ nylon thread. This sample holder was kept immersed in water, taking care to allow only the nylon thread, which delivers the sample weight to the balance, to cross the water surface.

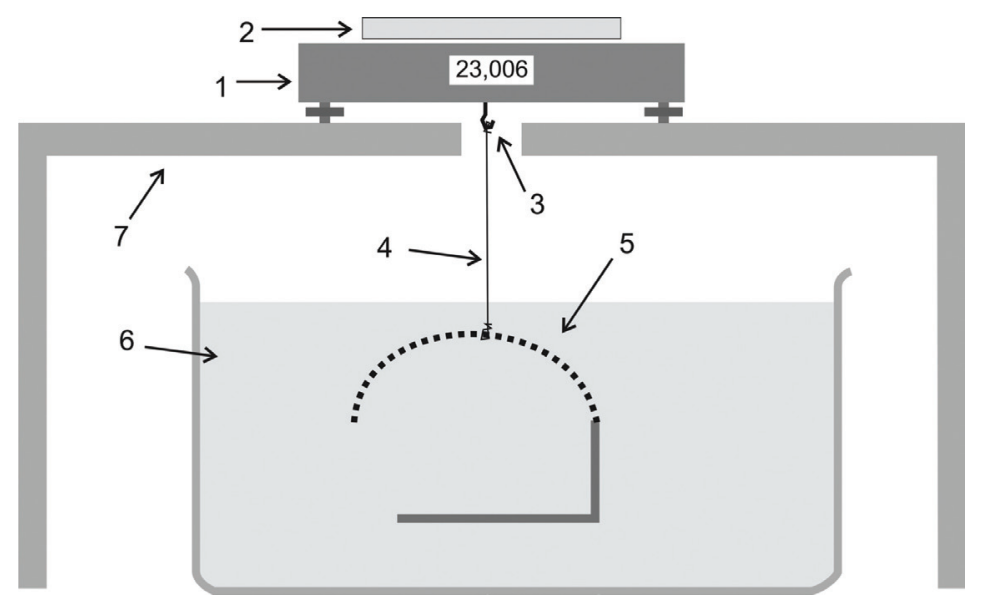

Figure 1. Hydrostatic weighing system components: 1- balance, 2- balance pan, 3- hydrostatic weighing hook, 4- nylon thread, 5- water immersed sample holder, 6 - water container, 7 - balance base. 
To obtain the weight $(m)$, the leaf surface was dried before weighing. The apparent weight $\left(m_{A}\right)$ was measured after placing a leaf segment inside the immersed sample holder (Figure 1). In this step, it was important to move the submerged leaf in the water to remove adhered air bubbles. After measuring $m$ and $m_{A}$, the leaf volume was estimated with the expression:

$$
v=\left(m-m_{A}\right) v_{\text {ew }} \quad \text { eq. } 6
$$

where $v_{e w}$ is the water specific volume, which was approximated to $1.00 \mathrm{~mL} \cdot \mathrm{g}^{-1}$.

Vacuum infiltration: For evaluating the water infiltration, half leaf segments, without the main vein, were introduced into a water-filled container and were held under water with aid of a cylindrical metallic weight. Then the container was closed and subjected to vacuum pressure for two minutes using an oil vacuum pump. After releasing the vacuum, a 15-minute infiltration was initiated. During this period, water was taken up by the vacuum-emptied intercellular volumes. Measurements of the apparent weight and water-infiltrated weight were done immediately after removing the leaves from the water.

Intercellular air volume: The intercellular air volume variation caused by leaf dehydration was measured using the following expression (Calbo and Nery, 1995b):

$$
\Delta v_{g}=\Delta v-\Delta m \cdot v_{e w} \quad \text { eq. } 7
$$

where $\Delta v_{g}$ is the intercellular air volume variation, $\Delta v$ is the leaf volume change (equation 6 ), $\Delta m$ is the leaf weight change, and $v_{e w}$ is the water specific volume.

During the water infiltration, the leaf intercellular air volume $\left(v_{g}\right)$ can be potentially reduced to zero. In this case, the intercellular air volume change is an estimate of the leaf intercellular air volume $\left(v_{g}\right)$ that the leaf had before the water infiltration. The weight of the water infiltrated inside the intercellular air volume $\left(m_{w}\right)$, can be obtained assuming that the intercellular air volume $\left(v_{g} / v\right)$ is equal to the intercellular volume after the leaf infiltration $\left(v_{g l} /\right.$
$\left.v_{I}\right)$; under this simplification, $m_{w}$ is calculated with the expression:

$$
m_{W}=m_{l}-v_{l} \cdot v_{g} /\left(m v_{\text {ew }}\right) \quad \text { eq. } 8
$$

\section{HYDRATION INDEX MEASUREMENTS}

Volumetric hydration and relative water content:

To obtain these indexes, leaf weight and volume were recorded during the assay, while measurements of $m_{l}$, $v_{l}$ and $m_{w}$ were done at the end of the experiment, as previously described. The volumetric hydration ( ${ }^{*} V$ ) was calculated with equation 4 , which uses measurements of leaf volume $(v)$ and leaf hydrated volume $v_{H}$, which, in turn, was obtained through the leaf water-infiltrated volume $\left(v_{I}\right)$. After the measurement of leaf dry weight $\left(m_{s}\right)$, measured after drying to a constant weight for $24 \mathrm{~h}$ at $104^{\circ} \mathrm{C}$, ${ }^{*} R$ was calculated using equation 3.

Turgor pressure: The leaf turgor pressure was estimated using a portable Wiltmeter ${ }^{\circledR}$ (Calbo \& Pessoa, 2009; Calbo et al., 2010). Measurements were made in regular leaf areas, avoiding surfaces with large veins and mechanical injuries. In addition, before the measurements, any water droplets or visible dust were removed from the adaxial leaf surface with a soft paper towel.

Leaf volumetric elastic modules: Strictly speaking, equation 5 would only be valid for ideal organs whose cells had thin cell walls or if only the organ symplasmic volume is considered (Husken et al., 1978; Murphy \& Ortega, 1995). Despite this, leaf volumetric elastic modules were used in a loose sense. Here, a few variations around such a definition were evaluated while following the weighing procedure of Murphy \& Ortega (1995) because the organ volume and its correspondent turgor pressure were reduced as a function of transpiration water loss. Evidently, just weighing is a reasonable approximation given the enormous experimental difficulties to measure plant symplasm volume, which would be a more exact variable 
to apply to the concept of leaf volumetric elastic modules. Accordingly, the following approximations were used to estimate leaf volumetric elastic modules: first, leaf volume; second, replacing $(v)$ by leaf mass $(m)$ in equation 5 ; third, relative water content; and fourth, leaf volume minus the intercellular air volume change.

\section{RESULTS AND DISCUSSION}

The possibility of evaluating leaf hydration without making reference to leaf mass at the harvest moment is valuable and can be done using the relative water content $\left({ }^{*} R\right)$ notion. This measurement, however, is toilsome and subject to errors of insufficient hydration and of sample growth (Slavick, 1974). To reduce the experimental errors and to accelerate the procedure, an adaptation of the water infiltration method of Czersky (1964 and 1968) to measure ${ }^{*} R$ (equation 3) was used in this study. The reduction of the hydration time to about 15 minutes has a practical value, and it is technically relevant to reduce the underestimation of the organ hydration produced when longer hydration periods of about one day are needed (Slavík, 1974).

The relative water content $\left({ }^{\star} R\right.$ ) estimated by this water infiltration method in kale leaves presented a linear relation with the applied transpiration water loss (Figure 2A). The intercept value, slightly smaller than one, immediately after harvest and before the leaf was subjected to water loss, seemed reasonable for an irrigated crop subject to a mild field water deficit. The intercept ${ }^{*} R$ value could be even closer to one, but our idea was to estimate the post-harvestinduced leaf water stress and not to study field leaf water stress, a subject that would demand a slightly different methodology to enable direct field observations. Regarding the post-harvest method, the organ growing error during the 15 min of water infiltration can be reduced not only by reducing the water absorption/infiltration period but also by doing water infiltration at low temperature, which, according to Proseus et al. (1999), would greatly reduce the growing rate. This temperature reduction approach, however, was not applicable because it would demand a longer infiltration time, not only because the water viscosity nearly doubles when the water temperature is reduced from $25{ }^{\circ} \mathrm{C}$ to 0 ${ }^{\circ} \mathrm{C}$ (Nobel, 1991) but also because the cell absorption rate can be greatly reduced by such a temperature reduction. Kramer (1940) observed in tomato roots that the water permeability was reduced more than ten times when the temperature was reduced from $25^{\circ} \mathrm{C}$ to $5^{\circ} \mathrm{C}$.

Besides the relative water content $\left({ }^{\star} R\right)$, the cell turgor pressure was also linearly reduced as a function of the leaf weight loss (Figure 2B) from $310 \mathrm{kPa}$, in recently harvested leaves, to zero, in leaves that have lost, by transpiration, about $23 \%$ of their initial weight. However, to consider kale as a valuable and attractive leaf product, it needs a minimum turgor pressure threshold value of about $150 \mathrm{kPa}$ (Spricigo et al., 2009). During this dehydration, the turgor pressure and the relative water content decreased in a linear fashion, starting at ${ }^{*} R$ equal to 0.94 and ending at a value of 0.70 (Figure 2C).

Another sign of the effect of water stress on kale leaves was the reduction of the intercellular air volume from a pre-stress value of $18.9 \%$ to $13.3 \%$ ( $\mathrm{v} / \mathrm{v}$; Figure 2D). The linear reduction of the leaf intercellular air volume is an indication that the water stress caused distortions in the geometric pattern of kale cells; otherwise, the intercellular air volume is fraction should have remained constant. In other words, the loss of cell turgor pressure, which is visually manifested as wilting, was caused by deformations of leaf cellular and intercellular lattices. In contrast to kale leaves, in other species, water stress can cause organ volume changes without causing deformation because the intercellular volume (v/v) remains constant; such near equilibrium stresses are said to occur under stable intercellular air volume state conditions (Calbo \& Nery, 2001). Therefore, signs of stress, such as wilting, are more difficult to see. 

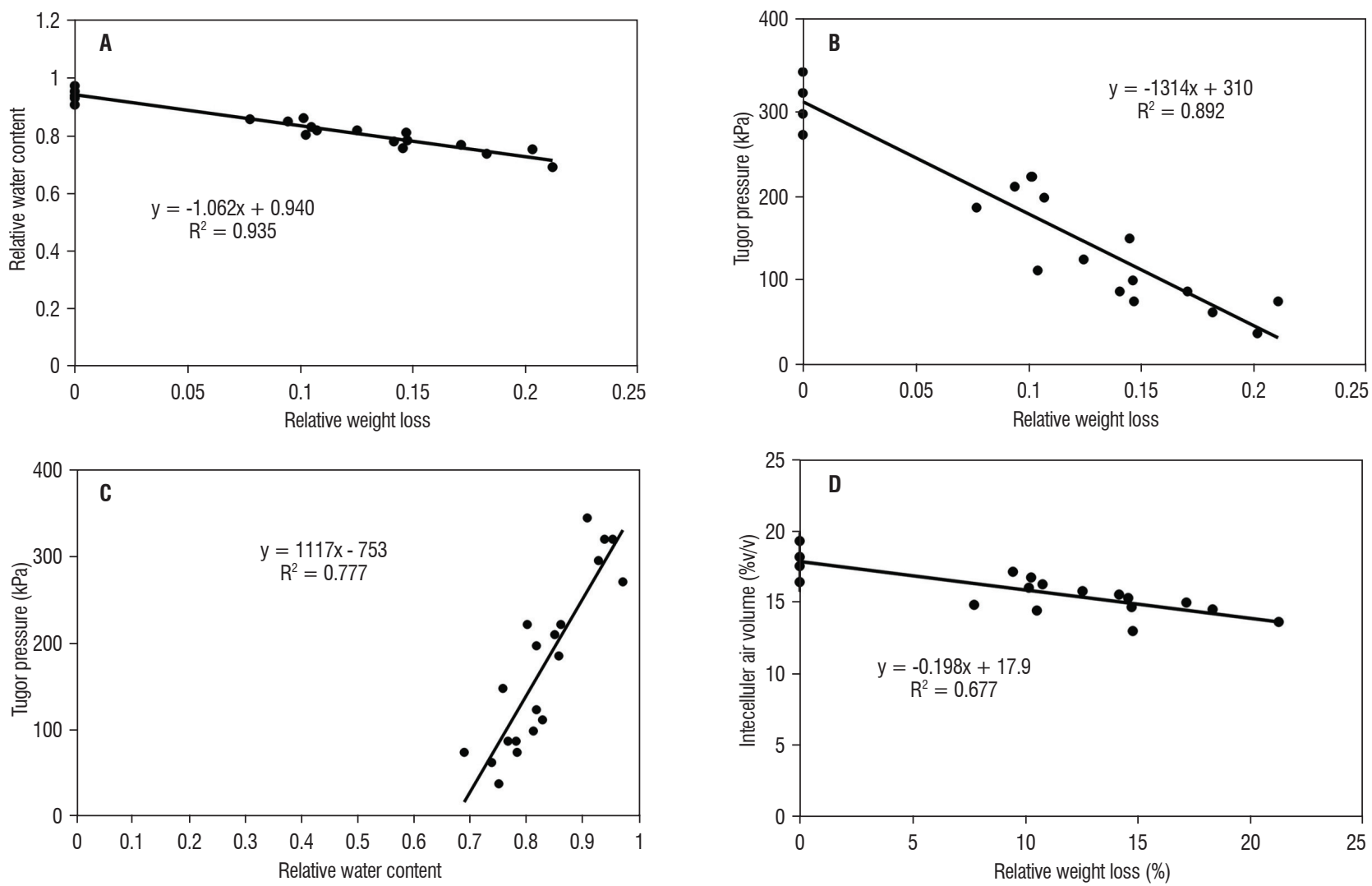

Figure 2. A- Relationship between weight loss after harvest and relative water content in kale leaves. B- Leaf turgor pressure as a function of relative weight loss; C- Influence of relative water content on turgor pressure; D- Intercellular air volume as a function of water loss.

By evaluating dehydration using only measurements of volume, such as the volumetric hydration index $\left({ }^{*}\right)$, it was observed that dehydration occurred in proportion to the water loss (Figure $3 \mathrm{~A}$ ) and to the relative water content (Figure 3B). Interestingly, the coefficients of these observations were unexpectedly high, which might be due to the relationship

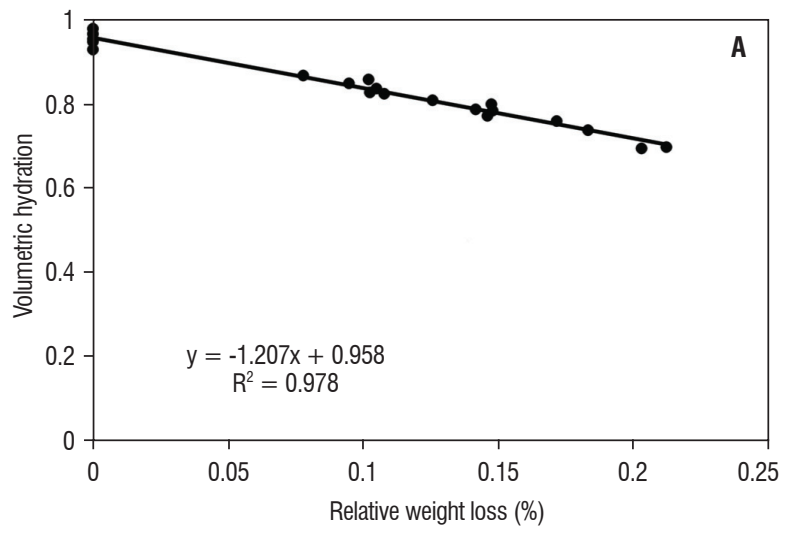

between water loss indexes and organ volume (equation 4) and organ mass (equation 3). The computational differences between equations 3 and 4 , which involve different sources of error, caused a slight difference in the coefficient of determination observed in figures $3 \mathrm{~A}$ and $\mathrm{B}$. This fact supports the claim that ${ }^{*} V$ is technically equivalent to ${ }^{*} R$ as a water stress index.

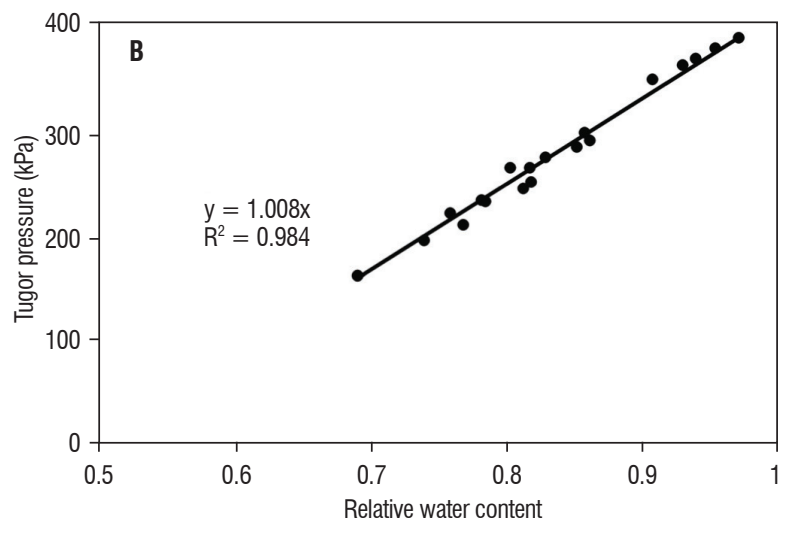

Figure 3. Volumetric hydration of kale leaves as a function of water loss (A) and as a function of the relative water content (B). 
The volumetric elastic module is a parameter that has been functionally defined using slightly different formulas (Figure 4) and using the Murphy \& Ortega (1995) approach, which causes changes in this parameter only by transpirationinduced water loss. Presumably, this procedure causes smaller cellular deformations than those methods that study leaf volumetric elastic modules by introducing fluids inside plant cells with the aid of capillary pressure probes (Hüsken et al., 1978). Such methods cause deformation in a single cell without causing deformations in its neighboring cells. Another important methodological simplification used in this study was the measurement of leaf cell turgor pressure with the Wiltmeter ${ }^{\circledR}$, which enables a rapid assessment of leaf hydration. Therefore, by simply fitting equation 5 to values of turgor pressure and leaf volume changes, different estimates of leaf volumetric elastic modules values were obtained for kale leaves.

Based on measurements of ${ }^{*} V$ (Figure $4 \mathrm{~A}$ ) or ${ }^{*} R$ (Figure $4 \mathrm{~B})$, the volumetric elastic modules were approximately $900 \mathrm{kPa}$. Larger leaf volumetric elastic modules values $(1,187 \mathrm{kPa})$ were observed as a function of leaf fresh weight (Figure $4 \mathrm{C}$ ) because the relative weight variation of leaf segments were smaller (Figure $3 \mathrm{~A}$ ). The larger relative variation of ${ }^{*} \mathrm{~V}$ in comparison with the relative variation in weight was caused by the reduction in the percentage of intercellular air volume during kale leaves dehydration (Figure 4). The similarity between leaf volumetric elastic modules obtained using ${ }^{*} R$ and ${ }^{*} V$ is interesting because the $* V$ calculation (equation 3 ) only involves changes in leaf volume, and the calculation of ${ }^{*} R$ (equation 4 ) involves the variation in leaf water content, while the dry weight $\left(m_{w}\right)$, presumably, remained constant. Consequently, if the volume and mass of leaves could possibly change in the same proportion, then, it would be demonstrated that leaf volumetric elastic modules measured as a function of ${ }^{*} R$ would be smaller than leaf volumetric elastic modules calculated as function of $* V$. This demonstration, however, was not possible; the explanation for such deviation was the reduction of the intercellular air volume because its reduction made the leaf volumetric hydration lower than the leaf relative weight as a function of transpiration. The confirmation of such explanation was obtained by calculating leaf volumetric elastic modules in a procedure where the intercellular air volume variation was disregarded. In our results (Figure 4D), leaf volumetric elastic modules as a function of cell volume change was 10\% higher. In addition, the comparison between figures $4 \mathrm{C}$ and $4 \mathrm{D}$ revealed that leaf volumetric elastic modules based only on weight were systematically higher; however, they were obtained with a smaller experimental standard error.

The best way to estimate volumetric elastic modules, then, seems to depend on the researcher's perspective: the first method uses the concept of individual cylindrical cells subject to volume changes with the aid of a pressure probe and less exact uses of this theory with prismatic cells inside typical plant organs; the second extends the leaf volumetric elastic modules definition to fit pressure versus organ volume changes obtained with a Scholander pressure pump (Boyer, 1985); and the third uses pragmatic estimations of leaf volumetric elastic modules of whole leaves to obtain results that can be used in plant breeding and ecophysiological research programs, which, in the near future, will take advantage of the Wiltmeter ${ }^{\circledR}$ instrument.

In the first case, equation 5 is appropriate, and it can be used with the pressure probe procedures of Hüsken et al. (1978). Similarly, a previous application of this theory was used to measure turgor pressure in giant Nitella algae cells (Green et al., 1971). However, a particular application of leaf volumetric elastic modules to individual cells in the middle of plant tissues induced changes in the presumed initial shape of these cells, caused by the induction of pressure difference among neighboring cells (Murphy \& Ortega, 1995).

The second case, leaf volumetric elastic modules fit to data of applied air pressure versus leaf water loss using a Scholander pressure chamber (Boyer, 1985), involves fitting specific plant-oriented mathematical models that can range from simple simplified linearization procedures to sophisticated models with several parameters that are fit by non-linear minimization procedures (Calbo \& Calbo, 1989). Furthermore, the low reliability of each fitted parameter tends to be an important limitation of these methods.

In the third case, the objective is to obtain leaf volumetric elastic modules $(E)$ according to transpiration water loss using a Wiltmeter ${ }^{\circledR}$ reading, which represents an average tissue pressure across the leaf lamina. In this regard, it is important to mention that theoretical estimations (as in Calbo \& Nery, 2001) of such phenomena (Calbo et al, 2010) that use flattening pressure, as in older articles, are always slightly smaller than the average cell turgor pressure measured with a cell pressure probe. Therefore, a Wiltmeter instrument measures an average pressure of a leaf as a whole organ. 
One alternative to reduce the observed variability caused by measurements made in different leaves (Figure 4) is the use of repeated measurements on a single leaf, which can be done, for example, when the leaf weight
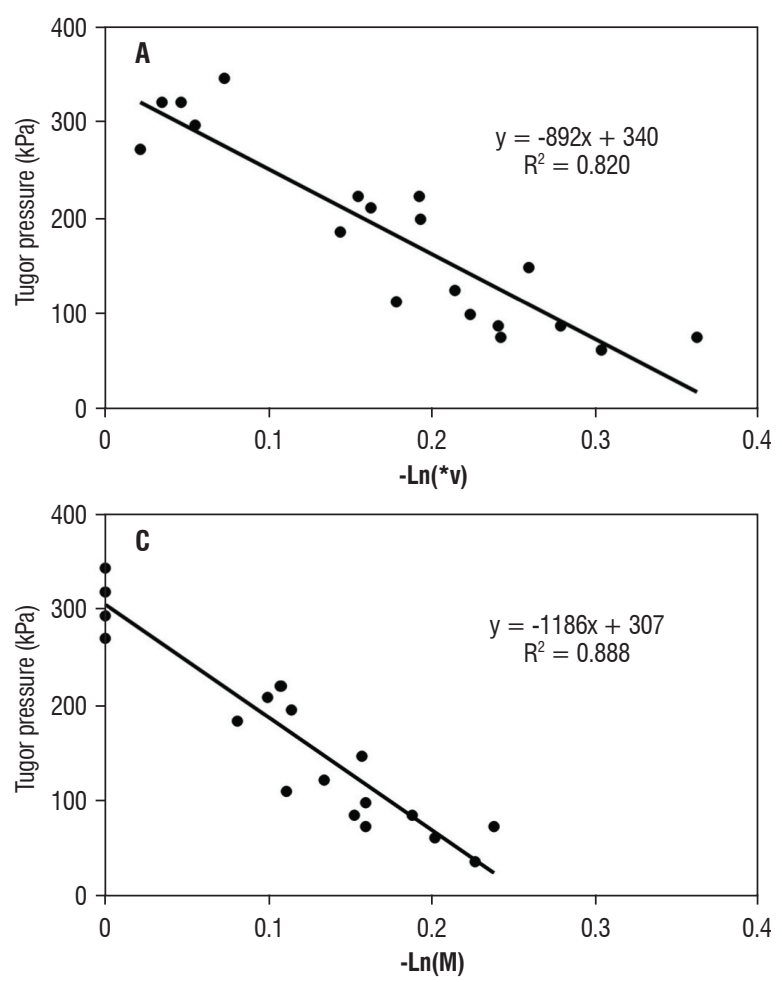

is the independent variable. Here, the use of a Wiltmeter instrument versus the weighing procedure is an adaptation of the Murphy \& Ortega (1995) method to measure turgor pressure.
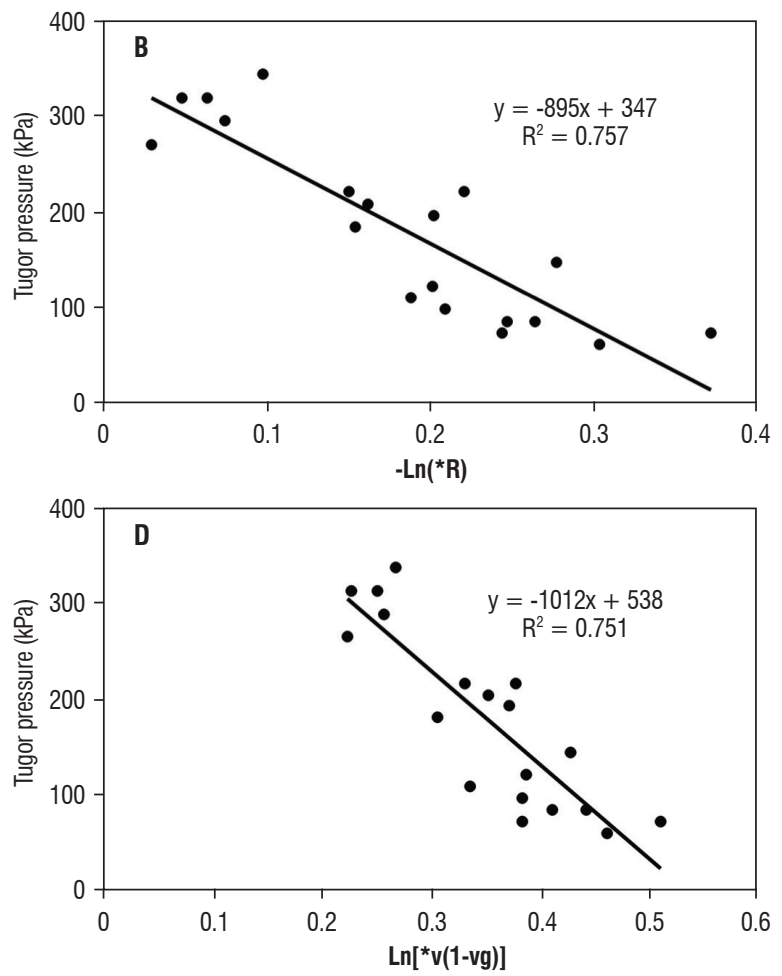

Figure 4. Declines in curves $A, B, C$ and $D$ are estimates of leaf volumetric elastic modules of kale according to A- the natural logarithm of volumetric hydration $\left({ }^{*} \mathrm{v}\right)$; B- the natural logarithm of relative water content; C- the natural logarithm of relative leaf weight; and D- the natural logarithm of volumetric hydration minus leaf intercellular volume.

\section{CONCLUSION}

Measurements of cell turgor pressure with a Wiltmeter ${ }^{\circledR}$ instrument are more accurate in comparison with other studied methods to evaluate plant hydration. In addition, it enables rapid and even repeated measurements in the same leaf. Moreover, this portable instrument can easily be taken to the field. Measurements of volumetric hydration and relative water content, both adapted from the original method of Czersky (1968) to achieve speediness and reliability, could be considered reference procedures to measure plant hydration. These methods, however, are toilsome and might be more difficult to use than the traditional methods requiring slow tissue water absorption from a moist substrate because these measurements involve tissue water infiltration after a vacuum treatment and hydrostatic weighing. Therefore, the newer methodology would become friendlier if, at least, the hydrostatic weighing procedure could be replaced by a simple and rapid image analysis method.

\section{REFERENCES}

Boyer JS (1985) Water transport. Annu. Rev. Plant Phys. 36:473-516.

Calbo AG, Calbo ME (1989) Medição e importância do potencial de parede. Rev. Bras. Fisiol. Veg. 1:41-45.

Calbo AG, Ferreira MD, Pessoa JDC (2010). A leaf lamina compression method for estimating turgor pressure. HortScience 45:418-423.

Calbo AG, Nery AA (1994) Methods to measure gaseous volume in plants. Rev. Bras. Fisiol. Veg. 6:153-162.

Calbo AG, Nery AA (1995a) Medida de firmeza em hortaliças pela técnica de aplanação. Hortic. Bras. 13:14-18. 
Calbo AG, Nery AA (1995b) Methods for measurement of gas volume of fruits and vegetables. J. Am. Soc. Hortic. Sci. 120:217-221.

Calbo AG, Nery AA (2001) Compression Induced Intercellular Shaping for Some Geometric Cellular Lattices. Braz. Arch. Biol. Techn. 44:41-48, 2001.

Calbo AG, Nery AA, Herrmann PSP (1995) Intercellular deformation in compressed organs. Ann. Bot. 76:365-370.

Calbo AG, Pessoa JDC (2009) Applanation system for evaluation of cell pressure dependent firmness on leaves and soft organs flat face segments. Invention patent W02009/009850A1, 17 p.

Calbo AG, Pessoa JDC (1994) A plant growth re-analysis. An extension of Lockhart's equation to multicellular plants. Rev. Bras. Fisiol. Veg. 6:83-89.

Calbo MER, Moraes JAPV (1997) Fotossíntese, condutância estomática, transpiração e ajustamento osmótico de plantas de buriti submetidas a estresse hídrico. Rev. Bras. Fisiol. Veg. 9:117-123.

Czersky J (1964) Gasometric method of volume determination of intercellular space in plant tissue. Acta Soc. Bot. Pol. 33:247-262.

Czersky J (1968) Gasometric method of water defict measurement in leaves. Biol. Plantarum 10:275-283.

Ferreira MD, CALBO AG (2008) Leitura de firmeza de folhas em Wiltmeter ${ }^{\circledR}$ é rápida e substitui medida de turgescência celular em sonda de pressão alface e couve. Hortic. Bras. 26:S4160-S4166.

Green PB, Erickson RO, Buggy J (1971) Metabolic and physical control of cell elongation rate. In vitro stuilies in Nitella. Plant Physiol. 47: 423-430.

Husken D, Steudle E, Zimmermann V (1978) Pressure probe technique for measuring water relations in higher plants. Plant Physiol. 61:158-163.

Husted S, Schjoerring JK (1995) Apoplastic pH and ammonium concentration in leaves of Brassica napus L. Plant Physiol. 109:1453-1460.

Kramer PJ (1940) Root resistance as a cause of decreased water absorption by plants at low temperatures. Plant Physiol. 15:53-79.
Lockhart JA (1965) An analysis of irreversible plant cell elongation. J.Theor. Biol. 8:264-275.

Murphy R, Ortega JKE (1995) A new pressure probe method to determine the average volumetric elastic modulus of cells in plant tissue. Plant Physiol. 107:995-1005.

Murphy R, Ortega JKE (1996) A Study of the stationary volumetric elastic modulus during dehydration and rehydration of stems of pea seedlings. Plant Physiol. 110:1309-1316.

Nobel PS (1991) Physicochemical and environmental plant physiology. Academic Press, San Diego 635p.

Pessoa JDC, Calbo AG (2004) Apoplasm hydrostatic pressure on growth of cylindrical cells. Braz. J. Plant Physiol. 16:17-24.

Proseus TE, Ortega JKE, Boyer JS (1999) Separating growth from elastic deformation during cell enlargement. Plant Physiol. 119:775-784.

Slavick B (1974) Methods of studying plant water relations New York, Springer-Verlag $449 \mathrm{p}$.

Spector WS (1956) Handbook of biological data Philadelphia (US), Saunders. $584 p$.

Spricigo PC, Ferreira MD, Calbo AG, Gutierrez ASD, Ferrari PR (2009) Aplicação do equipamento Wiltmeter ${ }^{\circledR}$ na mensuração da qualidade póscolheita de folhosa durante comercialização. Anais do 49 CBO - Hortic. Bras. 27:1-4.

Sun, DW (2008) Computer vision technology for food quality evaluation Elsevier Academic Press, San Diego, New York 600p.

Weisz PR, Randall HC, Sinclair TR (1989) Water relations of turgor recovery and restiffening of wilted cabbage leaves in the absence of water uptake. Plant Physiol. 91:433-439. 